\title{
Age-associated alterations in constitutively expressed cyclooxygenase- 2 immunoreactivity and protein levels in the hippocampus
}

\author{
HYO YOUNG JUNG ${ }^{1}$, DAE YOUNG YOO ${ }^{1}$, JONG WHI KIM ${ }^{1}$, HYUN JUNG KWON ${ }^{2}$, KWON YOUNG LEE ${ }^{3}$, \\ JUNG HOON CHOI ${ }^{3}$, DAE WON KIM ${ }^{2}$, JIN YOUNG CHUNG ${ }^{4}$, YEO SUNG YOON ${ }^{1}$ and IN KOO HWANG ${ }^{1}$ \\ ${ }^{1}$ Department of Anatomy and Cell Biology, College of Veterinary Medicine and Research Institute for Veterinary \\ Science, Seoul National University, Seoul 08826; ${ }^{2}$ Department of Biochemistry and Molecular Biology, Research \\ Institute of Oral Sciences, College of Dentistry, Gangneung-Wonju National University, Gangneung, Gangwon 25457; \\ Departments of ${ }^{3}$ Anatomy and ${ }^{4}$ Veterinary Internal Medicine and Geriatrics, College of Veterinary Medicine and \\ Institute of Veterinary Science, Kangwon National University, Chuncheon, Gangwon 24341, Republic of Korea
}

Received August 8, 2016; Accepted March 6, 2017

DOI: $10.3892 / \mathrm{mmr} .2017 .6512$

\begin{abstract}
Cyclooxygenase-2 (COX-2) is a known inducible inflammatory mediator. COX-2 is constitutively expressed in the hippocampus and may regulate synaptic plasticity. The present study investigated the age-associated alterations in white blood cell counts and hippocampal COX-2 expression in healthy mice using immunohistochemical and western blot analyses at 1 month postnatal (PM1), PM3, PM6, PM12 and PM24. White blood cell counts were significantly decreased in the PM24 group when compared with the PM1 group. In addition, lymphocyte counts were decreased in the PM24 group when compared with all other groups. By contrast, monocyte, neutrophil and eosinophil counts were increased in the PM24 group; however, this did not reach statistical significance. COX-2 expression was identified in the granule cells of the dentate gyrus and in the pyramidal cells of the hippocampal CA2/3 region. COX-2 immunoreactivity was maintained until PM18, however, the levels significantly decreased by PM24. These results suggest that, despite alterations in the differential white blood cell counts, the significant decrease in constitutive COX-2 expression in the hippocampus may be associated with degenerative age-associated alterations in synaptic plasticity in the hippocampus.
\end{abstract}

Correspondence to: Professor In Koo Hwang, Department of Anatomy and Cell Biology, College of Veterinary Medicine and Research Institute for Veterinary Science, Seoul National University, 85 dong, Gwanak-ro 1, Gwanak-gu, Seoul 08826, Republic of Korea E-mail: vetmed2@snu.ac.kr

Key words: cyclooxygenase-2, hippocampus, white blood cells, aging, mice

\section{Introduction}

Cyclooxygenases (COXs) are major inflammatory mediators that catalyze the production of thromboxane and prostaglandins from arachidonic acid. COXs consist of COX-1 and COX-2, and they possess $65 \%$ amino acid sequence homology and virtually identical catalytic sites (1). Among these, COX-2 has attracted the majority of attention, as it is induced by inflammation. COX-2 is constitutively expressed in specific organs, including the brain, thymus, gut and kidneys (2), and constitutive expression of $\mathrm{COX}-2$ in the brain is considered to serve a major role in synaptic plasticity, with prostaglandins generated by COX-2 modulating local cerebral blood flow and learning (3-6). Previous studies have demonstrated that treadmill exercise significantly increases neurogenesis and COX-2 immunoreactivity in the rat hippocampus $(7,8)$. In addition, the pharmacological or genetic inhibition of COX-2 significantly reduces constitutive COX-2 immunoreactivity, as well as the number of differentiated neuroblasts in the hippocampus $(7,9)$.

As life expectancy continues to increase, $20-30 \%$ of the population are likely to be $>65$ years of age by the year 2030 in the USA (10-12). Therefore, it is important to understand the alterations in physiological parameters and synaptic plasticity that occur during normal healthy aging, not just in neurodegenerative conditions. A number of previous studies have demonstrated that synaptic plasticity significantly decreases with increasing age in healthy animals (13-15).

Accumulating evidence has demonstrated that COX-2 is significantly upregulated in the brain of patients with Alzheimer's disease $(16,17)$. The administration of non-steroidal anti-inflammatory drugs reduces the risk of Alzheimer's disease (18-20). However, there are a limited number of studies investigating constitutive COX-2 immunoreactivity and protein levels in the hippocampus during aging of healthy individuals. Therefore, the aim of the present study was to investigate age-associated alterations in COX-2 immunoreactivity and protein levels in the hippocampus in naive healthy mice. 


\section{Materials and methods}

Experimental animals. A total of 50 male mice [postnatal month (PM)1; 14-17 g, PM3; 25-28 g, PM6; 28-32 g, PM12; 31-36 g, PM24; 30-34 g] were purchased from Japan SLC Inc. (Shizuoka, Japan). They were housed under standard conditions with adequate temperature $\left(22^{\circ} \mathrm{C}\right)$ and humidity $(60 \%)$ control, 12-h light/12-h dark cycles and access to food and water $a d$ libitum. The handling and care of the animals conformed to the guidelines established to comply with current international laws and policies (National Institutes of Health Guide for the Care and Use of Laboratory Animals, NIH Publication No. 85-23, 1985, revised 1996) and were approved by the Institutional Animal Care and Use Committee of Seoul National University (Seoul, Republic of Korea). Animals were equally divided into the following 5 groups ( $\mathrm{n}=10$ in each group): PM1, PM3, PM6, PM12 and PM24 groups. All experiments were conducted in an effort to minimize the number of animals used and the suffering caused by the procedures employed.

Blood sampling. The blood from mice in each group was used for immunohistochemical and western blot analyses, and was retrieved from the retro-orbital sinus for collection in blood collection tubes containing 3.8\% sodium citrate. Total blood cell counts were measured using the HEMAVET ${ }^{\circledR} 950$ (Drew Scientific Inc., Miami Lakes, FL, USA) within $5 \mathrm{~h}$ after collection. The analyzer required a volume of $20 \mu \mathrm{l}$ of whole blood for a successful measurement; therefore, 50-60 $\mu \mathrm{l}$ of blood was collected. Blood sample was maintained at $25^{\circ} \mathrm{C}$ for at least $5 \mathrm{~min}$ prior to measurement in order to stabilize the cells.

Tissue processing. For histological analysis, the animals $(\mathrm{n}=5$ in each group) at PM1, 3, 6, 12 and 24 were anesthetized with intraperitoneal injection of $1.5 \mathrm{~g} / \mathrm{kg}$ urethane (Sigma-Aldrich; Merck KGaA, Darmstadt, Germany) and the blood was retrieved from the retro-orbital sinus and collected in tubes containing $3.8 \%$ sodium citrate. The animals were perfused transcardially with $0.1 \mathrm{M}$ phosphate-buffered saline (PBS, $\mathrm{pH}$ 7.4) followed by $4 \%$ paraformaldehyde in $0.1 \mathrm{M}$ PBS $(\mathrm{pH}$ 7.4). The brains were removed and postfixed in the same fixative at $25^{\circ} \mathrm{C}$ for $12 \mathrm{~h}$ prior to undergoing cryoprotection via overnight storage in $30 \%$ sucrose. Serial coronal brain sections (30- $\mu \mathrm{m}$ in thickness) were generated using a cryostat (Leica Microsystems $\mathrm{GmbH}$, Wetzlar, Germany) and transferred to 6-well plates containing PBS for further processing.

Immunohistochemistry. In order to ensure that the immunohistochemical data were comparable between groups, sections were carefully processed under parallel conditions. Tissue sections located at a distance of $90 \mu \mathrm{m}$ from each other were selected from an area between 1.46 and $2.46 \mathrm{~mm}$ posterior to the bregma, as defined by a mouse atlas (21). A total of 10 samples of tissue sections located at a distance of $90 \mu \mathrm{m}$ from each other were sequentially incubated with $0.3 \%$ hydrogen peroxide in PBS for 30 min and $10 \%$ normal goat serum (S-1000, Vector Laboratories, Inc., Burlingame, CA, USA) in $0.05 \mathrm{M}$ PBS for $30 \mathrm{~min}$ at $25^{\circ} \mathrm{C}$. Sections were then incubated with a rabbit anti-COX-2 antibody (dilution, 1:200; cat. no. 160126; Cayman Chemical Company, Ann Arbor, MI, USA) overnight at room temperature. Sections were then incubated with biotinylated goat anti-rabbit $\operatorname{IgG}$ secondary antibody (dilution, 1:200; cat. no. BA-1000; Vector Laboratories, Inc.) for $2 \mathrm{~h}$ at $25^{\circ} \mathrm{C}$, followed by a streptavidin-peroxidase complex (dilution, 1:200; cat. no. SA-5004; Vector Laboratories, Inc.) for $1 \mathrm{~h}$ at room temperature. Immunostaining was visualized by reaction with $3,3^{\prime}$-diaminobenzidine $(1 \mathrm{mg} / \mathrm{ml}$ in $0.1 \mathrm{M}$ Tris- $\mathrm{HCl}$ buffer; $\mathrm{pH}$ 7.2). Sections were dehydrated and mounted on gelatin-coated slides in Canada balsam (Kanto Chemical, Co., Inc. Tokyo, Japan).

Analysis of the hippocampal CA2/3 region and dentate gyrus was performed using an image analysis system and ImageJ software (version 1.50; National Institutes of Health, Bethesda, MD, USA). Digital images of the mid-point of each region were captured using an Olympus BX51 light microscope (Olympus Corporation, Tokyo, Japan) equipped with a digital camera (DP72; Olympus Corporation) connected to a computer monitor. Images were calibrated into an array of $512 \times 512$ pixels corresponding to a tissue area of $1,200 \times 900 \mu \mathrm{m}$ (primary magnification, $\mathrm{x} 100$ ). Each pixel resolution was 256 gray levels and the intensity of COX-2 immunoreactivity was evaluated by the relative optical density (ROD), which was obtained following transformation of the mean gray level using the following formula: $R O D=\log _{10}(256 /$ mean gray level). The ROD of background staining was determined using the unlabeled portions of the sections using Photoshop CC 2015 software (Adobe Systems Inc., San Jose, CA, USA), and this value was subtracted to correct for nonspecific staining using ImageJ software (version, 1.50; National Institutes of Health). Data are expressed as a percentage of the PM1 group values (set to $100 \%$ ).

Western blot analysis. To quantify alterations in COX-2 expression levels in the hippocampus, animals were euthanized with intraperitoneal injection using $1.5 \mathrm{~g} / \mathrm{kg}$ urethane (Sigma-Aldrich; Merck KGaA) at PM1, 3, 6, 12 and $24(\mathrm{n}=5$ from each group) and their brains were removed. Tissues were dissected for use in western blot analysis. Briefly, brain tissue sections (500- $\mu \mathrm{m}$ in thickness) were produced using a vibratome (Leica Microsystems $\mathrm{GmbH}$ ) and the hippocampal region was dissected out using a surgical blade. Hippocampal tissues were homogenized in $50 \mathrm{mM}$ PBS (pH 7.4), containing $0.1 \mathrm{mM}$ ethylene glycol-bis (2-aminoethylether)-N,N,N', $\mathrm{N}^{\prime}$-tetraacetic acid $(\mathrm{pH} 8.0), 0.2 \%$ Nonidet P- $40,10 \mathrm{mM}$ ethylenediaminetetraacetic acid ( $\mathrm{pH} 8.0), 15 \mathrm{mM}$ sodium pyrophosphate, $100 \mathrm{mM} \beta$-glycerophosphate, $50 \mathrm{mM} \mathrm{NaF}, 150 \mathrm{mM}$ $\mathrm{NaCl}, 2 \mathrm{mM}$ sodium orthovanadate, $1 \mathrm{mM}$ phenylmethylsulfonyl fluoride and $1 \mathrm{mM}$ dithiothreitol (DTT). Following centrifugation for $5 \mathrm{~min}$ at $16,000 \mathrm{x}$ g at $4^{\circ} \mathrm{C}$, the protein levels in the supernatants were determined using a Micro BCA Protein assay kit (Pierce; Thermo Fisher Scientific, Inc., Waltham, MA, USA) according to the manufacturer's protocols. Aliquots containing $20 \mu \mathrm{g}$ total protein were denatured by boiling in loading buffer containing $150 \mathrm{mM}$ Tris (pH 6.8), $3 \mathrm{mM}$ DTT, $6 \%$ sodium dodecyl sulfate, $0.3 \%$ bromophenol blue and $30 \%$ glycerol. Each aliquot was loaded onto a $12 \%$ polyacrylamide gel. Following electrophoresis, proteins were transferred to nitrocellulose membranes (Pall Corporation, Port Washington, NY, USA), which were then blocked in $5 \%$ non-fat dry milk in PBS containing $0.1 \%$ Tween 20 for $45 \mathrm{~min}$ at $25^{\circ} \mathrm{C}$. Membranes were subsequently incubated with 
Table I. Age-associated alterations in white blood cell counts in C57BL/6 mice.

\begin{tabular}{lccccc}
\hline Cell count $($ cells $/ \mu \mathrm{l})$ & PM1 & PM3 & PM6 & PM12 & PM24 \\
\hline White blood cells & $3,282 \pm 296$ & $3,101 \pm 263$ & $3,158 \pm 285$ & $2,869 \pm 259$ & $2,471 \pm 301^{\mathrm{a}}$ \\
Lymphocytes & $2,820 \pm 275$ & $2,571 \pm 284$ & $2,683 \pm 280$ & $2,410 \pm 273$ & $1,629 \pm 225^{\text {a-d }}$ \\
Monocytes & $52.3 \pm 7.4$ & $46.9 \pm 6.9$ & $58.4 \pm 8.2$ & $62.1 \pm 8.5$ & $99.7 \pm 19.4$ \\
Neutrophils & $385.6 \pm 48.2$ & $401.3 \pm 41.7$ & $418.7 \pm 49.8$ & $488.1 \pm 63.8$ & $720.8 \pm 115.2$ \\
Eosinophils & $13.6 \pm 1.79$ & $14.5 \pm 2.02$ & $12.7 \pm 1.75$ & $13.3 \pm 2.08$ & $14.2 \pm 2.38$ \\
Basophils & $3.1 \pm 1.3$ & $3.7 \pm 1.1$ & $3.5 \pm 1.6$ & $4.3 \pm 1.3$ & $5.6 \pm 1.5$
\end{tabular}

${ }^{\mathrm{a}} \mathrm{P}<0.05$ vs. $\mathrm{PM} 1$ group; ${ }^{\mathrm{b}} \mathrm{P}<0.05$ vs. $\mathrm{PM} 3$ group; ${ }^{\mathrm{C}}<0.05$ vs. $\mathrm{PM} 6$ group; ${ }^{\mathrm{d}} \mathrm{P}<0.05$ vs. $\mathrm{PM} 12$ group. $\mathrm{PM}$, postnatal month.
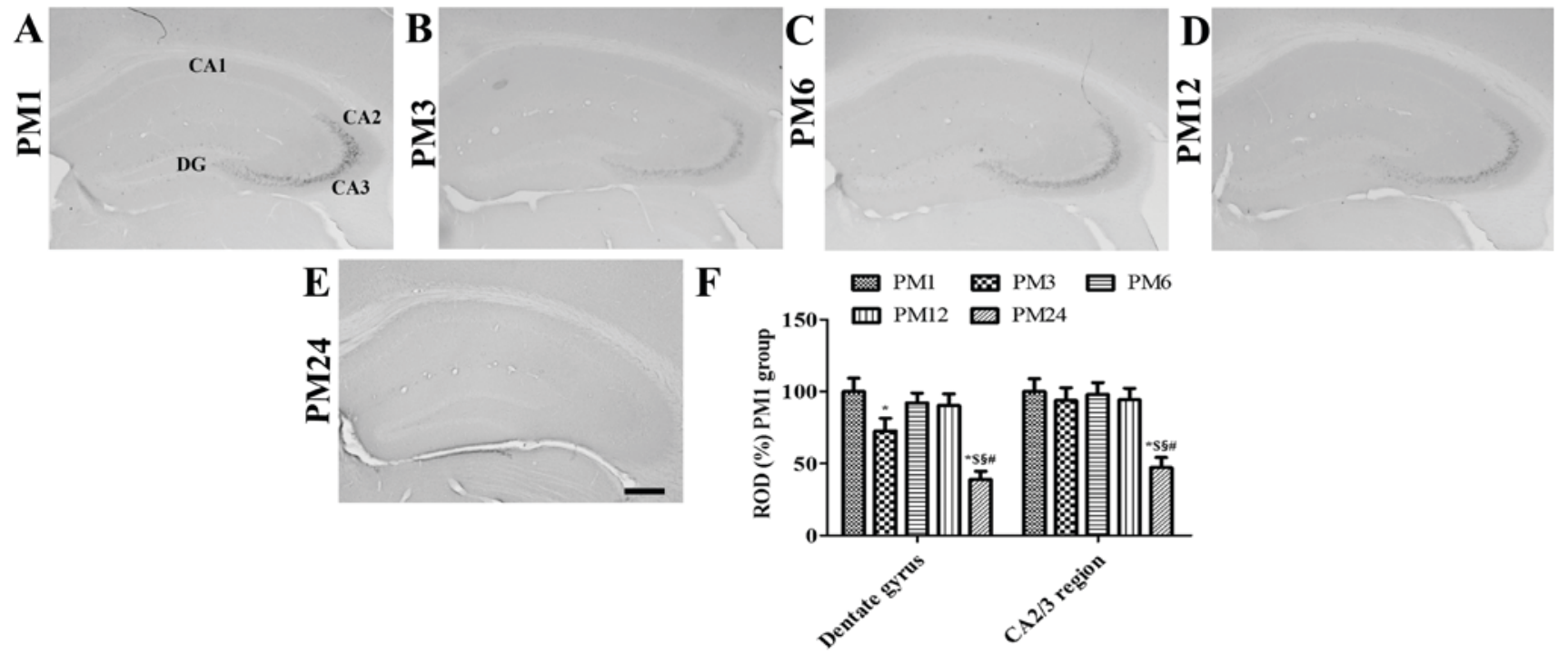

Figure 1. Immunohistochemical staining for COX-2 in the mouse hippocampus in the (A) PM1, (B) PM3, (C) PM6, (D) PM12 and (E) PM24 groups (scale bar, $200 \mu \mathrm{m}$ ). COX-2 immunoreactivity was constitutively observed in the granule cell layer of the DG and the SP of the hippocampal CA2/3 region. Of note, COX-2 immunoreactivity was significantly decreased in these regions in the PM24 group. (F) ROD values for each section are expressed as a percentage of the COX-2 immunoreactivity detected in the dentate gyrus and hippocampal CA2/3 region of mice in the PM1 group (n=5/group; ${ }^{*} \mathrm{P}<0.05$ vs. PM1 group; ${ }^{\circledR} \mathrm{P}<0.05$ vs. PM3 group; ${ }^{\circledR} \mathrm{P}<0.05$ vs. PM6 group; ${ }^{"} \mathrm{P}<0.05$ vs. PM12 group). Data are presented as the mean \pm standard error. COX-2, cyclooxygenase-2; ROD, relative optical density; PM, postnatal month; DG, dentate gyrus; SP, stratum pyramidale.

a rabbit anti-COX-2 antibody (dilution, 1:500; cat. no. 160126; Cayman Chemical Company) overnight at $4^{\circ} \mathrm{C}$. Detection was performed using peroxidase-conjugated anti-rabbit IgG (dilution 1:200; cat. no. PI-1000; Vector Laboratories, Inc.) for $2 \mathrm{~h}$ at $25^{\circ} \mathrm{C}$ and an enhanced luminol-based chemiluminescent kit (Pierce; Thermo Fisher Scientific, Inc.) for $1 \mathrm{~min}$. The blots were scanned, and densitometry analysis was performed using Scion Image software (version 4.0.3; Scion Corporation, Walkersville, MD, USA). Blots were stripped and reprobed with an antibody against $\beta$-actin (dilution 1:2,000; cat. no. ab8227; Abcam, Cambridge, UK) overnight at $4^{\circ} \mathrm{C}$ as an internal loading control. Data were normalized to the $\beta$-actin level in each lane.

Statistical analysis. Data are presented as the mean \pm standard error. Differences among the means of each group were analyzed by one-way analysis of variance followed by a Bonferroni's post hoc test using GraphPad Prism software (version 5.01; GraphPad Software, Inc., La Jolla, CA, USA). P<0.05 was considered to indicate a statistically significant difference.

\section{Results}

Age-associated alterations in white blood cell counts. The total white blood cell count began to decrease from PM12, and was significantly decreased in the PM24 group when compared with the PM1 group (Table I). Similarly, the lymphocyte count was significantly decreased in the PM24 group when compared with that of the PM1, PM3, PM6 and PM12 groups. By contrast, monocyte, neutrophil, eosinophil and basophil counts demonstrated a tendency to increase in the PM24 group, however, this did not reach statistical significance when compared with the other groups (Table I).

COX-2 immunoreactivity. In the PM1 group, COX-2 immunoreactivity was identified in particular granule cells of the dentate gyrus in addition to the pyramidal cells of the hippocampal CA2/3 region (Fig. 1A). In the PM3 to PM12 groups, the pattern of COX-2 immunoreactivity distribution was similar to that observed in the PM1 group. However, COX-2 immunoreactivity in the dentate gyrus was significantly 

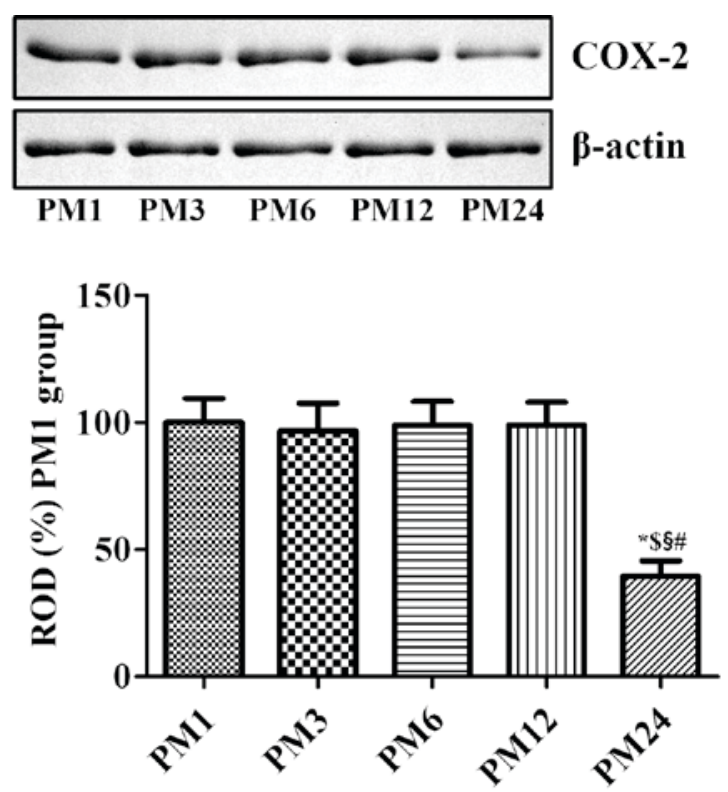

Figure 2. Western blot analysis of COX-2 expression, which is expressed relative to COX-2 expression in the PM1 group and normalized to $\beta$-actin (n=5/group; ${ }^{*} \mathrm{P}<0.05$ vs. PM1 group; ${ }^{\$} \mathrm{P}<0.05$ vs. $\mathrm{PM} 3$ group; ${ }^{\circledR} \mathrm{P}<0.05$ vs. $\mathrm{PM} 6$ group; ${ }^{\mathrm{P}}<0.05$ vs. $\mathrm{PM} 12$ group). Data are presented as the mean \pm standard error. COX-2, cyclooxygenase-2; ROD, relative optical density; PM, postnatal month.

decreased in the PM3 group when compared with the PM1 group (Fig. 1). COX-2 immunoreactivity was increased in the dentate gyrus of the PM6 group when compared with the PM3 group; however, COX-2 immunoreactivity was lower in the dentate gyrus of the PM6 group when compared with the PM1 group (Fig. 1). In the PM12 group, COX-2 immunoreactivity in the dentate gyrus was similar to that of the PM6 group (Fig. 1). However, COX-2 immunoreactivity in the CA2/3 region was not significantly altered in the PM1 to PM12 group. In the PM24 group, COX-2 immunoreactivity was significantly decreased in the dentate gyrus and the hippocampal CA2/3 region when compared to the other groups (Fig. 1). In this group, weak COX-2 immunoreactivity was identified in the hippocampal CA1 region.

COX-2 protein levels. Western blot analysis of brain tissue sections from mice in the PM1, PM3, PM6, PM12 and PM24 groups demonstrated results similar to the immunohistochemical analysis of COX-2 expression in the hippocampus. COX-2 protein levels were significantly decreased in the hippocampal homogenates of the PM24 group when compared with the other groups (Fig. 2).

\section{Discussion}

COX-2 is an inducible inflammatory mediator, which is constitutively expressed in the brain, kidney, gut and thymus (2). In particular, the constitutive expression of COX-2 is enriched in the hippocampus and cortex (3). In the brain, basal expression of COX-2 is regulated by N-methyl- $D$-aspartate receptor-dependent synaptic activity. In addition, induction of long-term potentiation by high-frequency stimulation increases COX-2 expression (22).
Previous studies have demonstrated that constitutive COX-2 expression is closely associated with neuroblast differentiation in the dentate gyrus $(7,9)$. The present study observed age-associated alterations in constitutive COX-2 expression in the hippocampus. COX-2 immunoreactivity was identified in the granule cells of the dentate gyrus, and the pyramidal cells of the hippocampal CA2/3 region. This result is consistent with previous studies involving mice and rats $(7,9)$. In humans, significant neuronal COX-2 immunoreactivity has been identified in the $\mathrm{CA} 3$ region, subiculum, entorhinal cortex and transentorhinal cortex (17). The present study demonstrated that COX-2 immunoreactivity was significantly decreased in the dentate gyrus and hippocampal CA2/3 region of PM24 mice when compared with younger mice. This result was supported by those of a previous study, which demonstrated that COX protein levels are reduced in the aged (18 months of age) cortex of male and female rats when compared with sex-matched young ( 3 months of age) rats (23). In addition, COX-2 mRNA levels were observed to be significantly decreased at PM30, and not at PM24, in hippocampal homogenates, with a 2-fold increase in brain thromboxane $\mathrm{B}_{2}$ levels in PM24 and PM30 groups (24). However, in the female rhesus monkey, COX-2 protein levels in the hippocampus were maintained at a constant level with increasing age, while COX-2 protein levels were significantly decreased in the frontal pole of middle-aged (8-11 years of age) rhesus monkeys when compared with younger (2-5 years of age) monkeys (25).

A previous study revealed a significant increase in COX-2 immunoreactivity in the gerbil hippocampal CA1 region in PM18 and PM24 groups when compared with PM1, PM3, PM6 or PM12 groups (26). However, this increase in COX-2 immunoreactivity was not observed in additional brain regions. These results contrast those of the present study, and may be associated with the inflammatory status of the animals. The present study confirmed that mice were not in a state of inflammation using white blood cell analysis. All white blood cell parameters were within the normal range in the PM24 group, although the lymphocyte counts were at baseline levels $(27,28)$. The parameters were similar to those identified in a previous study (29), which demonstrated that total white blood cell and lymphocyte counts decrease with age, while neutrophil, monocyte and eosinophil counts increase in mice. However, in humans, lymphocyte counts are significantly decreased in the first two decades and remain constant for the following three decades, and demonstrate a more prominent decrease thereafter (30).

In the present study, the observed decrease in COX-2 immunoreactivity in the hippocampus of aged mice may have been associated with decreased synaptic plasticity. Previous studies have identified that adult neurogenesis decreases with age (31-34). In addition, it was demonstrated that treadmill exercise increased neural plasticity and COX-2 expression in the dentate gyrus (7). Furthermore, the concentration of arachidonic acid in the cell membrane was significantly decreased in the hippocampus of aged (22 months of age) rats compared with that of younger adults (4 months of age) (35). Treatment with arachidonic acid ameliorated the age-associated impairments of long-term potentiation (35).

In conclusion, constitutive COX-2 expression was identified in the granule cells of the dentate gyrus and pyramidal cells 
of the hippocampal CA2/3 region in PM1, PM3, PM6, PM12 and PM24 mice. COX-2 expression was significantly reduced in these regions in PM24 mice in the absence of any significant increases in the white blood cell count, when compared with younger mice. These results suggest that a reduction in constitutive COX-2 expression may be correlated with an age-associated decrease in synaptic plasticity in the hippocampus.

\section{Acknowledgements}

The present study was supported by the Basic Science Research Program through the National Research Foundation of Korea, funded by the Ministry of Education (grant no. NRF-2013R1A1A2059364). In addition, the current study was supported by the Research Institute for Veterinary Science of Seoul National University.

\section{References}

1. Radi ZA: Comparative pathophysiology and toxicology of cyclooxygenase. John Wiley \& Sons, Hoboken, pp15-19, 2012.

2. Kirkby NS, Zaiss AK, Urquhart P, Jiao J, Austin PJ, Al-Yamani M, Lundberg MH, MacKenzie LS, Warner TD, Nicolaou A, et al: LC-MS/MS confirms that COX-1 drives vascular prostacyclin whilst gene expression pattern reveals non-vascular sites of COX-2 expression. PLoS One 8: e69524, 2013.

3. Yamagata K, Andreasson KI, Kaufmann WE, Barnes CA and Worley PF: Expression of a mitogen-inducible cyclooxygenase in brain neurons: Regulation by synaptic activity and glucocorticoids. Neuron 11: 371-386, 1993.

4. Li DY, Hardy P, Abran D, Martinez-Bermudez AK, Guerguerian AM, Bhattacharya M, Almazan G, Menezes R, Peri KG, Varma DR and Chemtob S: Key role for cyclooxygenase-2 in PGE2 and PGF2alpha receptor regulation and cerebral blood flow of the newborn. Am J Physiol 273: R1283-R1290, 1997.

5. Hewett SJ, Bell SC and Hewett JA: Contributions of cyclooxygenase-2 to neuroplasticity and neuropathology of the central nervous system. Pharmacol Ther 112: 335-357, 2006.

6. Lacroix A, Toussay X, Anenberg E, Lecrux C, Ferreirós N, Karagiannis A, Plaisier F, Chausson P, Jarlier F, Burgess SA, et al: COX-2-derived prostaglandin E2 produced by pyramidal neurons contributes to neurovascular coupling in the rodent cerebral cortex. J Neurosci 35: 11791-11810, 2015.

7. Hwang IK, Yi SS, Yoo KY, Park OK, Yan B, Kim IY, Kim YN, Song W, Moon SM, Won MH, et al: Effects of treadmill exercise on cyclooxygenase- 2 in the hippocampus in type 2 diabetic rats: correlation with the neuroblasts. Brain Res 1341: 84-92, 2010.

8. Hwang IK, Yi SS, Song W, Won MH, Yoon YS and Seong JK: Effects of age and treadmill exercise in chronic diabetic stages on neuroblast differentiation in a rat model of type 2 diabetes. Brain Res 1341: 63-71, 2010.

9. Nam SM, Kim JW, Yoo DY, Choi JH, Kim W, Jung HY, Won MH, Hwang IK, Seong JK and Yoon YS: Comparison of pharmacological and genetic inhibition of cyclooxygenase-2: Effects on adult neurogenesis in the hippocampal dentate gyrus. J Vet Sci 16: 245-251, 2015.

10. Vincent GK and Velkoff VA (eds): The next four decades: The older population in the United States: 2010 to 2050, In: United States Department of Commerce, C.B. (edition), Washington, DC, 2010.

11. Wimo A, Jönsson L, Bond J, Prince M and Winblad B; Alzheimer Disease International: The worldwide economic impact of dementia 2010. Alzheimers Dement 9: 1-11.e3, 2013.

12. Alzheimer's Association: 2014 Alzheimer's disease facts and figures. Alzheimers Dement 10: e47-e92, 2014.

13. Drapeau E, Mayo W, Aurousseau C, Le Moal M, Piazza PV and Abrous DN: Spatial memory performances of aged rats in the water maze predict levels of hippocampal neurogenesis. Proc Natl Acad Sci USA 100: 14385-14390, 2003.

14. Marlatt MW, Philippens I, Manders E, Czéh B, Joels M, Krugers $\mathrm{H}$ and Lucassen PJ: Distinct structural plasticity in the hippocampus and amygdala of the middle-aged common marmoset (Callithrix jacchus). Exp Neurol 230: 291-301, 2011.
15. Puzzo D, Bizzoca A, Loreto C, Guida CA, Gulisano W, Frasca G, Bellomo M, Castorina S, Gennarini G and Palmeri A: Role of F3/contactin expression profile in synaptic plasticity and memory in aged mice. Neurobiol Aging 36: 1702-1715, 2015.

16. Yokota O, Terada S, Ishihara T, Nakashima H, Kugo A, Ujike H, Tsuchiya K, Ikeda K, Saito Y, Murayama S, et al: Neuronal expression of cyclooxygenase-2, a pro-inflammatory protein, in the hippocampus of patients with schizophrenia. Prog Neuropsychopharmacol Biol Psychiatry 28: 715-721, 2004.

17. Fujimi K, Noda K, Sasaki K, Wakisaka Y, Tanizaki Y, Iida M, Kiyohara Y, Kanba S and Iwaki T: Altered expression of COX-2 in subdivisions of the hippocampus during aging and in Alzheimer's disease: The Hisayama Study. Dement Geriatr Cogn Disord 23: 423-431, 2007.

18. McGeer PL, Schulzer M and McGeer EG: Arthritis and anti-inflammatory agents as possible protective factors for Alzheimer's disease: A review of 17 epidemiologic studies. Neurology 47: 425-432, 1996.

19. Miguel-Alvarez M, Santos-Lozano A, Sanchis-Gomar F, Fiuza-Luces C, Pareja-Galeano H, Garatachea N and Lucia A: Non-steroidal anti-inflammatory drugs as a treatment for Alzheimer's disease: A systematic review and meta-analysis of treatment effect. Drugs Aging 32: 139-147, 2015.

20. Malkki H: Alzheimer disease: NSAIDs protect neurons and preserve memory in a mouse model of AD. Nat Rev Neurol 12: 370-371, 2016.

21. Franklin KBJ and Paxinos G: The mouse brain in stereotaxic coordinates. 3rd edition. Academic Press, San Diego, 1997.

22. Bliss TV and Collingridge GL: A synaptic model of memory: Long-term potentiation in the hippocampus. Nature 361: 31-39, 1993.

23. Sanguino E, Roglans N, Alegret M, Sánchez RM, Vázquez-Carrera $\mathrm{M}$ and Laguna JC: Prevention of age-related changes in rat cortex transcription factor activator protein-1 by hypolipidemic drugs. Biochem Pharmacol 68: 1411-1421, 2004.

24. Aïd S and Bosetti F: Gene expression of cyclooxygenase-1 and $\mathrm{Ca}(2+)$-independent phospholipase $\mathrm{A}(2)$ is altered in rat hippocampus during normal aging. Brain Res Bull 73: 108-113, 2007.

25. Weerasinghe GR, Coon SL, Bhattacharjee AK, Harry GJ and Bosetti F: Regional protein levels of cytosolic phospholipase A2 and cyclooxygenase-2 in Rhesus monkey brain as a function of age. Brain Res Bull 69: 614-621, 2006.

26. Lee CH, Yoo KY, Choi JH, Park OK, Hwang IK, Kang IJ and Won MH: Cyclooxygenase-2 immunoreactivity and protein level in the gerbil hippocampus during normal aging. Neurochem Res 35: 99-106, 2010.

27. Quinby FL: Clinical chemistry of the laboratory mouse. In: Fox JG (ed.) The mouse in biomedical research. 2nd ed., Vol. 3. Elsevier, Academic Press, Amsterdam, pp171-216, 2007.

28. Suckow MA, Danneman P and Brayton PC: The laboratory mouse. The laboratory animal pocket reference series. CRC Press, Boca Raton, 2001.

29. Hemmeryckx B, Emmerechts J, Bovill EG, Hoylaerts MF and Lijnen HR: Effect of ageing on the murine venous circulation. Histochem Cell Biol 137: 537-546, 2012.

30. MacKinney AA Jr: Effect of aging on the peripheral blood lymphocyte count. J Gerontol 33: 213-216, 1978.

31. Kuhn HG, Dickinson-Anson H and Gage FH: Neurogenesis in the dentate gyrus of the adult rat: Age-related decrease of neuronal progenitor proliferation. J Neurosci 16: 2027-2033, 1996.

32. Hwang IK, Yoo KY, Li H, Choi JH, Kwon YG, Ahn Y, Lee IS and Won MH: Differences in doublecortin immunoreactivity and protein levels in the hippocampal dentate gyrus between adult and aged dogs. Neurochem Res 32: 1604-1609, 2007.

33. Hwang IK, Yoo KY, Yi SS, Kwon YG, Ahn YK, Seong JK, Lee IS, Yoon YS and Won MH: Age-related differentiation in newly generated DCX immunoreactive neurons in the subgranular zone of the gerbil dentate gyrus. Neurochem Res 33: 867-872, 2008.

34. Seib DR and Martin-Villalba A: Neurogenesis in the normal ageing hippocampus: A mini-review. Gerontology 61: 327-335, 2015.

35. McGahon B, Clements MP and Lynch MA: The ability of aged rats to sustain long-term potentiation is restored when the age-related decrease in membrane arachidonic acid concentration is reversed. Neuroscience 81: 9-16, 1997. 